\title{
Effectiveness of cognitive style and learner control in hypermedia learning environments
}

Egbedokun, Adeola Oyebisi $\$

Obafemi Awolowo University, Nigeria (adeolaoyeegbedokun@gmail.com)

Adeyanju, Joel Oluwafunmilade

Obafemi Awolowo University, Nigeria (oadeyan@oauife.edu.ng)

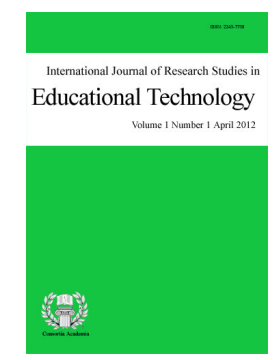

ISSN: $2243-7738$ Online ISSN: 2243-7746

OPEN ACCESS

\section{Abstract}

This study examined the effects of hypermedia instruction on Junior Secondary School (JSS) III learners' performance in Art History with consideration for learners'cognitive style. The study adopted the pretest posttest experimental design. The study sample was JSS 3 Fine Arts students purposively selected from six secondary schools. In selected schools, students from six intact Fine Arts classes were used. Students from four schools constituted four experimental groups while the other two remaining two schools constituted the two control groups. All groups consisted of field dependents and field independent learners. Data collected were analysed using Analysis of Variance (ANOVA) and Analysis of Covariance (ANCOVA). The analysis of variance statistics (ANOVA) showed that there was a significant difference between the two modes of hypermedia ( $\mathrm{MS}=79.625, \mathrm{~F}=13.838, p<0.05)$. Using analysis of covariance (ANCOVA) the result showed that there is no significant difference in the performance of field dependent and field independent when exposed to the modes of hypermedia ( $\mathrm{MS}=1.173, \mathrm{~F}=.300, p>0.05$ ). In conclusion, the study recommended that cognitive styles must be taken into consideration in order for learners to achieve maximally in hypermedia instructional procedure.

Keywords: hypermedia; learner control; cognitive style; performance; navigation 


\section{Effectiveness of cognitive style and learner control in hypermedia learning environments}

\section{Introduction}

Research findings and reports have outlined the importance of learners' cognitive styles in specific learning environments. Messick (1979) believes that this importance is stressed because cognitive styles are the representation of the preferences that individuals have for perceiving and processing information. Many of the reasons given as responsible for learners' low academic performance; such as large classes, lack, inappropriate or inadequate use of instructional media and strategies, may not be absolute. It is equally important that learners' perception of the environment and information processing style be taken into account. The concept of field dependence/independence as developed by Witkin, Moore, Goodenough, and Cox (1977) represents two constructs of cognitive styles that will be examined in this paper. McGee (1979) describes the field dependent person as one who tends to adhere to existing, externally imposed framework when presented with information while field independent person tend to restructure the information into a framework that seems more appropriate to make the information more meaningful and learnable. A large variety of cognitive style dimensions has been identified by researchers (Hodgkinson and Sadler-Smith, 2003) ranging from the well-known 'Field dependence' versus 'field independence' (Witkin et al., 1977), and 'serialist' versus 'holist' construct (Pask \& Scott, 1972) and 'levelers' versus 'sharpners' (Gardner, Holzman, Klein, Linton, \& Spence, 1959), and 'reflection' versus 'impulvist' (Kagan, 1965), to 'convergers' versus 'divergers' (Guilford, 1967) and 'adapters' versus 'innovators' (Kirton, 1976). Riding and Cheema (1991) observe that even though there are many different definitions of cognitive style as different researchers emphasize different aspects.

Triantafilllou Pomportsis, Demetriads, and Georgiaou (2004) carried out a study on whether students' performance could be influenced in an adaptive hypermedia environment using students' cognitive styles as independent variable. The researchers used 66 fourth year undergraduate studying the course "Multimedia Technology Systems" who volunteered to participate in the study. They were assigned into two groups: experimental (36 students) and control (30 students). The students were exposed to four lessons. Four instruments were used in the study: (i) Group Embedded Figures Test (GEFT)-to determine the cognitive style of the participants, (ii) Ten (10) open-ended question items to determine subject's prior knowledge on the domain (pre-test), (iii) An immediate post-test, which consisted of a performance test with the same items as the pre-test to verify any increase in understanding at the end of the instruction, and (iv) an attitude and acceptance questionnaire for the experimental group that included items relating to the completeness and ease of use of the system, and also items on subject's satisfaction and willingness to use the system. In order to ensure that both groups had the same prior knowledge on the domain, a test for homogeneity on the data of the pre-test was computed. As expected, the result of the ANOVA presented no significant effects. So, only the post-test was computed into the statistical analysis. A two-way analysis of variance (ANOVA), with alpha level set at .05, was used to test for main effects and the interaction assumption between learning environment and cognitive style. The results revealed a significant main effect for the learning environment. These findings indicate that students in experimental group performed significantly better than students in control group. Furthermore, these results provide the evidence that the adaptive educational system AES-CS, which was designed to provide improvement of students interactions and outcomes. On the contrary, the ANOVA result does not show significant main effect of cognitive style for the learner achievement. These results suggest that cognitive style alone did not impact on learner's performance. In addition, the results also indicated no significant interaction between learning environment and cognitive style.

A number of studies have earlier been carried out to investigate the effect of cognitive styles on hypermedia learning and have to some extent been consistent with the findings of Triantafilou, Pomportsis, Demetriadis, and Georgiadou (2014). The studies indicated that different cognitive style groups showed distinct reactions to 
non-linear interaction, which represents one of the major differences between hypermedia and traditional learning (Chen \& Macredie, 2002). Ford, Miller, and Moss (2001) investigated the relationship between cognitive style and problem solving and its associated information seeking showed that field-independent researchers were more analytic and active than their field-dependent counterparts and engaged more in exploratory and serendipitous (unprecedented) behavior, and were more idiosyncratic in their communication than serialists. Wang, Hawk, and Tenopir (2000) investigated how users search for factual information on the Web with a focus on individual differences. The user dimension, one of the dimensional factors in the study, was influenced by dynamic situational factors, such as the particular task, the information need, and the knowledge state of the user. In addition, certain individual characteristics influenced the human domain, including an individual's cognitive style and affective state before and throughout the interaction process. They found that differences in cognitive style affected search process; field-dependent individuals are likely to have greater difficult in the Web environment and to get confused more easily than field-independent individuals.

Palmquist and Kim (2000) studied the effects of cognitive style and experiences on Web searching. Search performance was measured in terms of time required and the number of nodes traversed to locate relevant information. The study showed that there was a relationship of cognitive style and experience on Web searching. Field-dependent novice searchers took longer and traversed more nodes in locating relevant information than field-independent novices. Kim and Allen (2002) investigated how students with different cognitive and problem-solving style navigated the Web. They found that cognitive style affected information searching strategies. Field independent students tended to engage in search tasks with more active and analytic strategies. Field dependent students in contrast did not feel comfortable with using tools for jumping around different nodes and navigate the Web in a linear mode.

Calcaterra, Antonietti, and Underwood (2005) examined the influence of cognitive style, spatial orientation and computer expertise on hypertext navigation patterns and learning outcomes when participants interacted with a hypermedia presentation. A sample of 306 undergraduates was pre-tested both on their cognitive style and on their self-reported frequency and ability in using computers. From the initial sample, 40 students were selected to form four groups with the following characteristics: (a) 10 high computer users - sequential thinkers, (b) 10 high computer users - holistic thinkers, (c) 10 low computer users - sequential thinkers and (d) 10 low computer users - holistic thinkers. All participants completed a self-report questionnaire measuring spatial orientation and were then requested to browse freely a hypermedia presentation on the ancient Mayan civilization. Finally, the students completed a post-test to assess the recall of the hypermedia presentation and the cognitive organization of the acquired knowledge. The results indicated that hypermedia navigation behavior was linked to computer skills rather than to cognitive style and that learning outcomes were unaffected by cognitive style or by computer skills. However, learning outcomes were positively affected by specific search patterns, that is, by re-visiting hypermedia sections and visiting overview sections in the early stages of hypermedia browsing. These findings suggest that individual differences can affect hypermedia navigation even though their role in learning is complex and the impact of cognitive style on learning outcomes was proved to be less important than initially predicted.

While, Chuang (1999) examined the combined effect of three media factors (text, voice and computer animation) on 175 Taiwan seventh grade children's Mathematics achievement. It was found that the effect of a combination of animation, text and voice on mathematics achievement for field independent learners is greater than field dependent learners. Field independent learners benefit from greater media complexity. Liu and Reed (1994) carried out a study using sixty three (63) college students from a non-English speaking background. The sixty three college students were engaged in hypermedia-assisted language learning. The author found that field independent learners tended to create their own structure while working with the hypermedia setting whereas field dependent learners were more prone to follow the structure imposed by the software. In addition, field dependent learners developed a more spectator and social approach to learning. Field independent learners are more analytical in their approach to processing information whereas field dependent learners are more likely to employ a more global visual approach to learning. Weller, Repman, and Rooze (1994) studied the effect of 
hypermedia software on thirty three (33) eighth-grade students enrolled in computer literacy courses. It was found that field independent learners learned more effectively than field dependent learners. The authors also reported that the two groups appeared to differ in the way they accessed information. Field independent learners displayed stronger information-seeking behavior than field dependent learners. It was also concluded form the study that learning style interacts with outcomes and approaches to learning.

Literature has established that field independent learners perform better in the conventional instructional tasks than their field dependent counterparts (Handal \& Herrington, n.d.). Simonson (1985) found that field dependents learners are more influenced by the social environments rather than by their own motivation; appear to be more influenced by praise and criticism than field independent learners. In turn, field independents are more proactive and usually have a strong concept. Triantafilou, Pomportsis, Demetriadis, and Georgiadou (2004) describe field independent learners as generally analytical in perception and interpretation, whereas field dependent learners are more global in perception and interpretation. Handal and Herrington (n.d.) also found that hypermedia learning environments, such as multimedia, CD-ROMS and websites, provide an environment where field independent learners have more opportunities to succeed. It was however found that field dependent learners benefit from graphic-based instruction. As a result, Handal and Herington agree with Hall (2000) that field dependents learners are less verbal and may require alternative and more visual forms of instruction. However, this study is set to find out whether a hypermedia based instruction will improve performance of field dependent learners in either large or small class.

Hypermedia learning environments consist of network-like information structures, where fragments of information are stored in nodes that are interconnected and can be accessed by electronic hyperlinks (Rouet, Levonen, Dillon, \& Spiro, 1996). Landers and Reddock (2017) recognized the claims of hypermedia advocates that providing control of pace, sequence, content, and other elements to the learner individualizes instruction. From a cognitive theory framework learner control is assumed to promote elaboration since decisions made about instruction require deeper processing and reflection on the learning process. This decision making process is also assumed to promote elaboration, and allows learners to adjust the rate of encoding and processing to their level (Merrill, 1984; Williams, 1993). Reigeluth and Stein (1983) advocate “...informed learner control by motivated learners". The term "informed" implies both cognitive (processes) and metacognitive (knowledge of those processes) skills. However, the research literature concerning learner control and achievement does not bear out these expectations. While there are studies that both support and reject learner control as an effective instructional strategy, the vast majority report no significant difference (Chung \& Reigeluth, 1992; Steinberg, 1977; Steinberg, 1989; Williams, 1993).

In addition, Carrier and Williams (1988) summarize the research on learner control with the statement "...as a whole these findings present a montage of inconsistencies, contradictions, and caveats" (p. 286). Parsons (1991) concluded, in a meta-analysis of computer-based-instruction (CBI) learner control studies, that achievement under learner control was practically equivalent to program control. Two reasons are usually cited (outside of research flaws) to explain why learner control failed to improve achievement: students did not use appropriate learning and review strategies; and students were unable to manage their time and monitor their progress (Clark, 1985; Merrill, 1984; Steinberg, 1989). The result of this meta-analysis point to the fact that the learner is an essential factor in the success of learner controlled learning environments. Other findings from the research indicate that students with high ability and those with high levels of prior knowledge appear to benefit more than other types of students (Friend \& Cole, 1990; Williams, 1993). Subject matter also appears to influence the effectiveness of learner control treatments. Social oriented subjects with less specific rules and procedures usually showed more positive results under learner control. Domains that are more rule driven and require precise application of declarative knowledge such as math consistently resulted in less achievement for learner control treatments (Parsons, 1993; Steinberg, 1989; Williams, 1993).

Learner control is assumed to be a beneficial feature of hypermedia. Indeed, it is explicit in the definition offered by most researchers of hypermedia (Jonassen, 1989). However, hypermedia has the potential of creating 
even more cognitive and metacognitive problems than other systems that use learner control. The most often reported negative effects are "getting lost in hyperspace" and cognitive overload due to navigation decisions and trying to make sense of the database (Chung \& Reigeluth, 1992; Jonassen, 1991; Marchionini, 1988; Park, 1991). When learners are faced with navigation decisions in a huge data base the cognitive demand can consume mental resources that should be available for learning (Gray, 1987; Park, 1991; Tripp \& Roby, 1990). Many hypermedia links are either tangential or irrelevant which causes more confusion (Nelson \& Palumbo, 1992). In addition, many programs do not provide navigation trails or exit paths when they are needed (Cates, 1992). A study by Harmon (1993) found that some students moved to topics as quickly as possible because they did not want to forget the associations they were forming. Harmon also noted that learners' thought processes were interrupted when viewing content and making links, and they could not remember what associations they were developing or why.

Harmon and Dinsmore (1994) examined linking patterns by learners in a hypermedia program on Middle Eastern history. They found that the multiple-channel video segments seemed to thwart purposeful linking by the learners. The authors reported that after watching the video segments many learners became disoriented and confused. When given the option of choosing video segments only seven of the twenty-four participants chose video more than once. In a study by Liu (1994) students became confused when they could not remember which icon or menu item to use. In larger, more complex, and unstructured systems, getting lost or stranded is not uncommon for novices (Jonassen, 1991). The lack of effective and intuitive navigational tools and browsers also contributes to this situation (Park, 1991).

Several studies of hypermedia instruction have noted the absence of metacognitive ability in learners to monitor and assess their learning and take proper action to remedy their deficiencies (Jonassen, 1991; Lin, 1994; Weller et al., 1994). It is suggested that the lack of ability to assess their state of learning and take action to remedy their deficiencies leads to students missing important information, frustration, and incorrect conceptual links (Clark, 1983; Merrill, 1984; Park, 1991; Recker \& Pirolli, 1992). As a result, researchers have recently began to investigate not only the functional features of hypermedia but how these features interact with individual learners' characteristics.

\section{Method}

\subsection{Objectives}

The objectives of the study are to:

$>$ Examine the effectiveness of learner controlled and teacher controlled hypermedia instruction on students achievement

$>\quad$ Investigate the effect of cognitive style on learners performance in learner controlled and teacher controlled hypermedia instruction

\subsection{Hypothesis}

$>$ There is no significant difference in the achievement of students exposed to learner control, teacher control hypermedia instruction and those that were not

$>\quad$ There is no significant difference in the performance of field dependent and field independent learners exposed to learner controlled and teacher controlled hypermedia instruction.

\subsection{Sampling Procedure}

The sample for the study was purposively selected from six secondary schools (three of which were private 
Egbedokun, A. O., \& Adeyanju, J. O.

and the other three were public secondary schools). The schools that qualified for selection included schools that have functioning computer systems and have been teaching Fine Arts in JSS classes, for at least the last five years. Intact Fine Arts classes were used in the selected schools. Students from three schools constituted three experimental groups field dependent and field independent learners. Each school represented a group. All the six groups were exposed to the same topic in Fine Arts and the procedure lasted six weeks.

\subsection{Instruments}

The following three instruments were used in the study: (i) Group Embedded Figures Test (GEFT) (Witkin et al., 1977). The Group Embedded Figures Test is a non-verbal test which requires that learners are shown a simple shape and a complex design within which the simple shape is hidden. The task is that learners will have to isolate the simple figure from the complex design. This instrument was administered in order to determine the cognitive styles of sample learners that were involved in the study. This instrument was administered during the first contact period. First, students were informed that the test did not attract any grade and that it was not a measure of intelligence, rather, it was meant to determine cognitive style. After this, the researcher read out the instructions and attempted to solve the examples. A duration of 40 minutes was allowed to find solution to the 20 figures. The requirement was that students would locate simple geometric figures embedded in more complex designs within the specified time limits. The estimate of reliability value of the GEFT has been put at 0.82 . GEFT scores range from 0 to 18 . Students who scored between 0 to 11 were classified as field dependent (FD) and those who scored between 12 to 18 were classified as field independent (FI). This study did not consider the field neutral (FN). (ii) Achievement Tests (Achievement Test in Fine Arts, ATFA). This second instrument was used to determine students' performance in Art History, those exposed to hypermedia-based instructional package and those that were not. It is a twenty-item multiple choice questions designed and administered by the researcher. This test was first administered as pretest to assess students' entry behavior and also as post test to measure performance, and administered as posttest at the end of the experiment to determine achievement/performance.

\section{Results}

Objective 1: The effectiveness of learner controlled and teacher controlled hypermedia instruction on learners' achievement

\section{Table 1}

T-test for equality of means of learner control and teacher control hypermedia instruction

\begin{tabular}{lccccccc}
\hline \multicolumn{1}{c}{ Mode of Hypermedia } & $N$ & Mean & $S D$ & $t$ & $d f$ & $\begin{array}{r}\text { Sig. }(2 \\
\text { tailed) }\end{array}$ & $\begin{array}{c}\text { Mean } \\
\text { difference }\end{array}$ \\
\hline Teacher Control & 52 & 11.19 & 2.47 & -3.72 & 102 & 0.00 & -1.75 \\
Learner Control & 52 & 12.94 & 2.32 & & & & \\
\hline
\end{tabular}

Table 2

Descriptive of the pre and post test

\begin{tabular}{llcccc}
\hline \multicolumn{1}{c}{ Mode of Instruction } & $N$ & Mean & SD & Std. Error \\
\hline \multirow{3}{*}{ Pretest } & Teacher control & 52 & 5.09 & 1.12 & .155 \\
& Learner control & 52 & 5.28 & 1.36 & .188 \\
& No Hypermedia & 52 & 5.36 & 1.17 & .162 \\
& Total & 156 & 5.25 & 1.22 & .097 \\
\hline \multirow{3}{*}{ Posttest } & Teacher control & 52 & 11.19 & 2.47 & .343 \\
& Learner control & 52 & 12.94 & 2.32 & .321 \\
& No Hypermedia & 52 & 9.90 & 1.49 & .207 \\
& Total & 156 & 11.34 & 2.46 & .197 \\
\hline
\end{tabular}


Effectiveness of cognitive style and learner control in hypermedia learning environments

Table 3

ANOVA summary of the means of the learner control hypermedia and teacher control hypermedia instruction

\begin{tabular}{llccccc}
\hline & & \multicolumn{1}{c}{$S S$} & $d f$ & Mean Square & $F$ & Sig. \\
\hline \multirow{2}{*}{ Pretest } & Between Groups & 2.000 & 2 & 1.000 & .667 & .515 \\
& Within Groups & 229.250 & 153 & 1.498 & & \\
& Total & 231.250 & 155 & & & \\
\multirow{5}{*}{ Posttest } & Between Groups & 241.885 & 2 & 120.942 & 26.381 & .000 \\
& Within Groups & 701.423 & 153 & 4.584 & & \\
& Total & 943.308 & 155 & & & \\
\hline
\end{tabular}

Table 1 shows the t-test analysis of the difference between learner control and teacher control hypermedia instruction. The mean scores obtained from learners exposed to the two modes of hypermedia instruction yielded a $\mathrm{p}$ value significant at .05 alpha (MD $-1.75, \mathrm{t}=-3.72, \mathrm{df}=102, p<0.05)$. Since there was a significant difference between the two means scores, with the learner control hypermedia instruction with the highest mean score, it implies that learner control hypermedia instruction was most effective in teaching Art History. This result, though excludes the learners in the control group, it was done to show specifically, what difference would be between the two groups exposed to the two modes of hypermedia. Results contained in table 2 compares the performance of students during pretest and posttest in the two experimental groups and the control group (pretest: $\mathrm{SS}=231.25, \mathrm{MS}=1.498, \mathrm{df}=2, \mathrm{~F}=.667, p>0.05$; posttest: $\mathrm{SS}=943.308, \mathrm{MS}=4.584, \mathrm{df}=2, \mathrm{~F}=.26 .381, p<0.05)$. The result indicates that the posttest performance of learners in the three groups were significantly different.

Objective 2: Investigate the effect of cognitive style on learners' performance in learner controlled and teacher controlled hypermedia instruction

\section{Table 4}

Descriptive of the dependent and independent learners factors of the two modes of hypermedia instruction

\begin{tabular}{llccc}
\hline Mode of Hypermedia & Cognitive Style & Mean & $S D$ & $N$ \\
\hline Teacher control hypermedia & FD & 10.42 & 2.45 & 26 \\
& FI & 11.96 & 2.28 & 26 \\
Learner control hypermedia & Total & 11.19 & 2.47 & 52 \\
& FD & 11.92 & 1.87 & 26 \\
& FI & 13.96 & 2.30 & 26 \\
No Hypermedia & Total & 12.94 & 2.32 & 52 \\
& FD & 9.15 & 1.12 & 26 \\
Total & FI & 10.65 & 1.46 & 26 \\
& Total & 9.90 & 1.49 & 52 \\
& FD & 10.50 & 2.19 & 78 \\
& FI & 12.19 & 2.44 & 78 \\
\hline
\end{tabular}

Note. ${ }^{*} \mathrm{NB}: \mathrm{FD}=$ Field Dependent, FI= Field Independent

Result in table 4 shows the descriptive statistics section of the hypothesis under analysis. The table shows that field dependent learners exposed to teacher controlled hypermedia had 10.42 mean score while field independent learners exposed to teacher controlled hypermedia had 11.96. Also, field dependent learners exposed to learner controlled hypermedia had 11.92 mean score while field independent learners exposed to learner controlled hypermedia had 13.96 . 
Egbedokun, A. O., \& Adeyanju, J. O.

\section{Table 5}

ANCOVA summary of the dependent and independent factors of the hypermedia-based instructional package

\begin{tabular}{llccccc}
\hline & Source & SS & df & Mean Square & F & Sig. \\
\hline Intercept & Hypothesis & 20082.692 & 1 & 20082.692 & 179.804 & .047 \\
& Error & 111.692 & 1 & $111.692(\mathrm{a})$ & & \\
Media & Hypothesis & 241.885 & 2 & 120.942 & 103.098 & .010 \\
& Error & 2.346 & 2 & $1.173(\mathrm{~b})$ & & \\
Cogsty & Hypothesis & 111.692 & 1 & 111.692 & 95.213 & .010 \\
& Error & 2.346 & 2 & $1.173(\mathrm{~b})$ & & \\
Media * Cogsty & Hypothesis & 2.346 & 2 & 1.173 & .300 & .742 \\
& Error & 587.385 & 150 & $3.916(\mathrm{c})$ & & \\
\hline
\end{tabular}

Table 4 shows the main effects of learner control and teacher control hypermedia instructional and cognitive styles (Modes of hypermedia $\mathrm{SS}=2.346, \mathrm{df}=2, \mathrm{MS}=1.173, \mathrm{~F}=103.098, p>0.05$ ); (Cognitive styles $\mathrm{SS}=2.346$, $\mathrm{df}=2, \mathrm{MS}=1.173, \mathrm{~F}=95.213, p>0.05)$ and interaction effects of modes of hypermedia and cognitive style ( $\mathrm{SS}=587.385, \mathrm{df}=150, \mathrm{MS}=3.916, \mathrm{~F}=.300, p>0.05$ ). These values did not yield any significant difference between field dependent and field independent learners exposed to modes of hypermedia and those that were not.

\section{Discussion}

\subsection{Effect of Hypermedia on performance}

This study has revealed that learner controlled hypermedia was effective in improving learners' performance. It afforded the learner the opportunity of interacting with the instructional contents, and learners were able to navigate through all the paths of the hypermedia environment (text, audio or video). Learners were also seen glued to the instructional content because it comprised of graphics for enriched learning experience. This is consistent with Chang and Ho (2009) who believe that learner controlled instruction, generally, affords learners to interact with their environment. It was indeed observed during the study that learners who were exposed to learner controlled hypermedia-based instructional package had better opportunity to go through the lesson at their own pace and had access to the various components of hypermedia (audio, texts, video and pictures). This finding also confirms the works of Hannafin and Sullivan, 1995; Chen and Macredie, 2002; El-Tigi and Branch, 1997; Gerjets and Scheiter 2003; Schmidt and Ford, 2003; Corbalan, Kester, and Merrienboer, 2006. Kopcha and Sullivan (2008) however summarized that this significant results have prompted instructional designers to consider the issue of learner control when designing instruction using the internet or hypermedia. This result thus places great responsibility on teachers of Art History to make use of learner controlled hypermedia-based instructional package in order to allow their learners achieve better in the class.

\subsection{Effect of cognitive style and Hypermedia on performance}

The result obtained here did not show a significant relationship between learners' cognitive style and the mode of hypermedia learners were exposed to. The performance of field independent learners did not differ from their field independent counterparts when exposed to the different modes of hypermedia. This finding is consistent with the result obtained by Chen and Rada (1996), in a meta-analysis that revealed no significant impact of cognitive styles on students' achievement despite their prominent role in the literature. Similar conclusions were drawn by Dillon and Gabbard (1998), Shih and Gamon (1999), Ford and Chen (2000). The result also was consistent with Oh and Lim (2005) study which indicated that online learners' cognitive styles are not significantly correlated with learner variables such as learners' attitudes, experience with online instruction, and their competency in computer technology. Scheiter and Gerjets (2007) however concluded that it is yet unclear whether the concepts themselves are not important to hypermedia learning, or whether 
methodological and conceptual problems have caused these no significant results (e.g., assessment methods with only low reliability and validity, inadequate subject samples etc.). The current study observed (though the hypermedia that was used in the current study did not record how learners accessed the package) the field dependents learners exposed to learner controlled hypermedia chose to access all the data formats on the package. The hypermedia was designed in both linear and nonlinear structure to cater for the two cognitive style structures.

\section{Conclusion}

The study has shown that learners' performance can be improved using learner controlled hypermedia because it has been found to be the most effective mode of hypermedia. The performance of learners under any mode of hypermedia has no significant relationship with cognitive style. That a learner is a field independent does not make him perform better than his field dependent counterparts when exposed to any mode of hypermedia. It is recommended that Hypermedia instruction should be adopted to teach Art History in secondary schools. Government should however encourage locally produced hypermedia instructional because it is only through locally produced that learners' needs in Nigeria could be taken care of. It should also be mentioned that learning through such hypermedia should be learner controlled. Even though this study did not establish any significant relationship between learners' cognitive style and hypermedia on performance. It is also imperative for teachers to make sure that this is taken care of in preparing hypermedia instruction. It is also recommended that more research efforts should be focused towards this direction.

\section{References}

Calcaterra, A., Antonietti, A., \& Underwood, J. (2005). Cognitive style, hypermedia navigation and learning. Retrieved from http://www.sciencedirect.com/science?_ob https://doi.org/10.1016/j.compedu.2004.04.007

Carrier, C. A., \& Williams, M. D. (1988). A test of one learner-control strategy with students of differing levels of task persistence. American Educational Research Journal, 25(2), 285-306. https://doi.org/10.3102/00028312025002285

Cates, W. M. (1992). Fifteen principles for designing more effective instructional hypermedia/multimedia products. Educational Technology, 32(12), 5-11.

Chang, M. M., \& Ho, C. M. (2009). Effects of locus of control and learner-control on web-based language learning. Computer Assisted Language Learning, 22(3), 189-206. https://doi.org/10.1080/09588220902920094

Chen, C., \& Rada, R. (1996). Interacting with hypertext: A meta-analysis of experimental studies. Human-Computer Interaction, 11, 125- 156. https://doi.org/10.1207/s15327051hci1102_2

Chen, S. Y., \& Macredie, R. D. (2002). Cognitive Styles and hypermedia navigation: Development of a learning model. Journal of the American Society for Information Science and Technology, 53(1), 3-15. https://doi.org/10.1002/asi.10023

Chuang, Y. R. (1999). Teaching in a multimedia computer environment: A study of the effects of learning style, gender, and math achievement [Electronic version]. Interactive Multimedia Electronic Journal of Computer-Enhanced Learning. Retrieved from http://imej.wfu.edu/articles/1999/1/10/index.asp

Chung, J., \& Reigeluth, C. M. (1992). Instructional prescriptions for learner control. Educational Technology, 32(10), 14-20.

Clark, R. E. (1983). Research on student process during computer-based instruction. Journal of Instructional Development, 7(3), 2-5. https://doi.org/10.1007/BF02905752

Conklin, J. (1987). Hypertext: An introduction and survey. IEEE Computer, 20, 17-41. https://doi.org/10.1109/MC.1987.1663693

Corbalan, G., Kester, L., \& Van Merriënboer, J.J.G. (2006). Towards a personalized task selection model with shared instructional control. Instructional Science, 34, 399-422. 
Egbedokun, A. O., \& Adeyanju, J. O.

https://doi.org/10.1007/s11251-005-5774-2

Dillon, A., \& Gabbard, R. (1998). Hypermedia as an educational technology: A review of the quantitative research literature on learner comprehension, control, and style. Review of Educational Research, 68(3), 322-349. https://doi.org/10.3102/00346543068003322

El-Tigi, M., \& Branch, R. M. (1997). Designing for interaction, learner control, and feedback during web-based learning. Educational Technology, 37(3), 23-29.

Ford, N., \& Chen, S.Y. (2000). Individual differences, hypermedia navigation and learning: An empirical study. Journal of Educational Multimedia and Hypermedia, 9(4), 281-312.

Friend, C. L., \& Cole, C. L. (1990). Learner control in computer-based instruction: A current literature review. Educational Technology, 20(11), 47-49.

Gardner, R. W., Holzman, P. S., Klein, G. S., Linton, H. B., \& Spence, D. P. (1959). Cognitive control: A study of individual consistencies in cognitive behavior. Psychological Issues, 1(4), 1-17.

Gerjets, P., \& Scheiter, K. (2003). Goal configurations and processing strategies as moderators between instructional design and cognitive load: Evidence from hypertext-based instruction. Educational Psychologist, 38(1), 33-41. https://doi.org/10.1207/S15326985EP3801_5

Gray, S. H. (1987). The effect of sequence control on computer assisted learning. Journal of Computer-Based Instruction, 14(2), 54-56.

Guilford, J. P. (1967). The nature of human intelligence. New York: McGraw-Hill.

Hall, J. K. (2000). Field dependence-independence and computer-based instruction in geography (Doctoral dissertation). Virginia Polytechnic Institute and State University.

Handal, B., \& Herrington, A. (n.d). On being dependent or independent in computer based learning environments.

Hannafin, R. D., \& Sullivan, H. J. (1995). Learner control in full and lean CAI programs. Educational Technology Research and Development, 43(1), 19-30. https://doi.org/10.1007/BF02300479

Harmon, S. W. (1993). On the nature of exploratory behavior in hypermedia environments: Considerations of learner use patterns for the design of hypermedia instructional systems (Doctoral dissertation), University of Georgia.

Harmon, S. W., \& Dinsmore, S. H. (1994). Novice linking in hypermedia-based instructional systems. Computers in the Schools, 10(2), 155-170. https://doi.org/10.1300/J025v10n01_11

Hodgkinson, G. P., \& Sadler, S. (2003). Complex or unitary? A critique and empirical re-assessment of the Allinson-Hayes Cognitive Style Index. Journal of Occupational and Organizational Psychology, 76(2), 279-281. https://doi.org/10.1348/096317903765913740

Jonassen, D. H. (1989). Performance analysis. Performance \& Instruction, 4, 15-23. https://doi.org/10.1002/pfi.4170280406

Jonassen, D. H. (1991). Hypertext as instructional design. Educational Technology Research and Development, 39(2), 83-92. https://doi.org/10.1007/BF02298109

Kagan, J. (1965). Reflection-impulsivity and reading ability in primary grade children. Child Development, 36(3) 609-628. https://doi.org/10.2307/1126908

Kim, K. S., \& Allen, B. (2002). Cognitive and task influences on web searching behavior. Journal of the American Society for Information Science and Technology, 53(2), 109-119. https://doi.org/10.1002/asi.10014

Kopcha T. J., \& Sullivan, H. (2008). Learner preferences and prior knowledge in learner-controlled computer-based. Instruction Educational Technology Research and Development, 56(3) 265-286. https://doi.org/10.1007/s11423-007-9058-1

Landers, R. N. \& Reddock, C. M. (2017). A meta-analytic investigation of objective learner control in web-based instruction. Journal of Business and Psychology, 32(4), 455-478. https://doi.org/10.1007/s10869-016-9452-y

Liu, M. (1994). Hypermedia assisted instruction and second language learning: A semantic-network -based approach. Computers in the Schools, 10, 293-312. https://doi.org/10.1300/J025v10n03_04

Liu, M., \& Reed, M.R. (1994) .The relationship between the learning strategies and learning styles in a 
Effectiveness of cognitive style and learner control in hypermedia learning environments

hypermedia environment. Computers in Human Behavior, 1(4), 419-434.

https://doi.org/10.1016/0747-5632(94)90038-8

Marchionini, G. (1988). Hypermedia and learning. Freedom and chaos. Educational Technology, 28(11), 8-12.

Merrill, M. D. (1984). What is learner control? In C. R. Dills (Ed.), Instructional development: The state of the art (Vol II, pp. 221-242). ERIC Document Reproduction Service No. ED298905.

Messick, S. (1979). Potential uses of noncognitive measurement in education. Journal of Educational Psychology, 7(1), 281-292. https://doi.org/10.1037/0022-0663.71.3.281

Nelson, W. A., \& Palumbo, D. B. (1992). Learning, instruction, and hypermedia. Journal of Educational Multimedia and Hypermedia, 1(1), 287-299.

Oh, E., \& Lim, D. (2005). Cross relationships between cognitive styles and learner variables in online learning environment. Journal of Interactive Online Learning, 4(1), 53-66.

Palmquist, R. A., \& Kim, K. S. (2000). Cognitive style and on-line database search experience as predictors of Web search performance. Journal of the American Society for Information Science and Technology, 51(6), 558-566. https://doi.org/10.1002/(SICI)1097-4571(2000)51:6<558::AID-ASI7>3.0.CO;2-9

Park, O. (1991). Hypermedia: Functional features and research issues. Educational Technology, 31(8), $24-31$.

Parsons, J. A. (1991). A meta-analysis of learner control in computer-based learning environments [Unpublished Doctoral Dissertation]. Nova University, Fort Lauderdale, FL.

Pask, G., \& Scott, B. (1972). Learning strategies and individual competence. International Journal of Man-Machine Studies, 4(3), 217-253. https://doi.org/10.1016/S0020-7373(72)80004-X

Recker, M. M., \& Pirolli, P. (1992). Student strategies for learning programming from a computational environment. In C. Frasson, G. Gauthier, \& G. I. McCalla (Eds.), Lecture notes in computer science: Intelligent tutoring systems (pp. 382-394). Berlin: Springer-Verlag. https://doi.org/10.1007/3-540-55606-0_46

Reigeluth, C. M., \& Stein, F. S. (1983). The elaboration theory of instruction. In C. M. Reigeluth (Ed.), Instructional-design theories and models (pp. 335-382). Hillsdale, NJ: Erlbaum.

Riding, R., \& Cheema, I. (1991). Cognitive styles-On overview and integration. Educational Psychology, 11(3/4), 193-215. https://doi.org/10.1080/0144341910110301

Rouet, J.-F., \& Levonen, J. J. (1996). Studying and learning with hypertext: Empirical studies and their implications. In J.-F. Rouet, J. J. Levonen, A. Dillon, \& R. J. Spiro (Eds.), Hypertext and cognition (pp. 9-23). Mahwah, NJ: Erlbaum.

Rouet, J.-F., Levonen, J. J., Dillon, A., \& Spiro, R. J. (1996). Hypertext and cognition. Mahwah, NJ: Erlbaum.

Scheiter, K., \& Gerjets, P. (2007). Learner control in hypermedia environments. Educational Psychology Review 19, 285-307. https://doi.org/10.1007/s10648-007-9046-3

Shih, C. C., \& Gamon, J. (1999). Student learning styles, motivation, learning strategies, and achievement in web-based courses. Proceedings of the $1^{\text {st }}$ Annual congress on the impact of technology upon learning. Winston-Salem, NC. Retrieved from http://iccel.wfu.edu/publications/journals/jcel/jcel990305.ccshih.htm

Steinberg, E. R. (1977). Review of student control in computer-assisted instruction. Journal of Computer-Based Instruction, 3(3), 84-90.

Steinberg, E. R. (1989). Review of student control in computer-assisted instruction. Journal of Computer-Based Instruction, 16(4), 117-124.

Triantafilllou, E., Pomportsis A., Demetriads S. \& Georgiaou E., (2004). The value of adaptivity based on cognitive style: an empirical study. British Journal of Educational Technology, 35(1), 95-106. https://doi.org/10.1111/j.1467-8535.2004.00371.x

Tripp, S. D., \& Roby, W. (1990). Orientation and disorientation in a hypertext lexicon. Journal of Computer Based Instruction, 17(4), 120-124.

Wang, P., Hawk, W. B., \& Tenopir, C. (2000). Users' interaction with world wide web resources: An exploratory study using a holistic approach. Information Processing and Management, 36, 229-251. https://doi.org/10.1016/S0306-4573(99)00059-X

Weller, H. G., Repman, J., \& Rooze, G. E. (1994). The relationship of learning, behavior, and cognitive style in 
Egbedokun, A. O., \& Adeyanju, J. O.

hypermedia based instruction: implications for design of HBI. Computers in the Schools, 10(3/4), 401-420. https://doi.org/10.1300/J025v10n03_09

Williams, M. D. (1993). A comprehensive review of learner-control: The role of learner characteristics. Paper presented at the annual convention of the Association for Educational Communications and Technology, New Orleans, LA.

Witkin, H. A., Moore, C. A., Goodenough, D. R., \& Cox, P. W. (1977). Field-dependent and field-independent cognitive styles and their educational implications. Review of Education Research, 47(1), 1-64. https://doi.org/10.3102/00346543047001001 